\title{
On Situating the Stance of Socio-cognitive Approach to Language Acquisition
}

\author{
Mohammad Khatib \\ Allameh Tabataba'i University, Tehran, Iran \\ Nima Shakouri \\ Roudbar Branch, Islamic Azad University, Rasht, Iran
}

\begin{abstract}
A growing number of studies that are founded on such socio-cognitive views have been undertaken in the past decade. Socio-cognitive approach attempts to compromise between the communication from pragmatic view and that from cognitive view, and has a strong inclination toward a dialectical approach. Not only is communication an intention-directed practice, but it also displays an attention-oriented traits. And socio-cognitive approaches attempt to make them closer. The paper is not in attempt to elaborate the difference between pragmatic and cognitive view of communication but to elucidate the shared feature of them in favor of socio-cognitive paradigm.
\end{abstract}

Index Terms—-socio-cultural, socio-cognitive, situated learning, restructuring

\section{INTRODUCTION}

The term socio-cognitive is raised by Atkinson (2002) as the social-cognitive hybrid (Matsuoka \& Evans, 2004). Atkinson calls it socio-cognitive, to emphasize the interplay between the patterns in the physical world and the social world to which we become attuned, and the patterns we develop and employ internally (cited in Mislevy, 2008). The social is related to what is going on in the outside world; the cognitive is related to what is going on the inside world. Hence, as to Meskill and Rangelov (2000), the term socio-cognitive grows an attempt to reconcile the social and affective side of learning with what happens in the black box as it were. Along the same line, within a socio-cognitive framework, learners are seen as dialectically connected to the social contexts in a synergetic relation (Meskill \& Rangelova, 2000). In fact, marshaling from the known to unknown takes place at the point where sociology and psychology intersects, and this intersection occurs when mind is mediated. The paper is in attempt to cast light upon the theoretical background of socio-cognitive linchpins in second language acquisition.

\section{LITERATURE REVIEW}

\section{A. Socio-cognitivists in Parallel with Socio-culturalists}

Long can be put from socio-cognitive and socio-cultural perspectives to second language acquisition, but what causes a bone of contention is the shared pedestal between. From socio-cognitive perspective, human behavior is the result of integration of mediation into human activity. This activity might be either psychological or social. Henceforth, to some extent, it is plausible to use socio-cognitive instead of Vygotskan's socio-cultural framework. However, there are some essential differences. The differences proposed by practitioners (e.g., Glaveanu, 2011) are not contradictory, but complementary. Among the features signifying the differences between socio-cognitive models and socio-cultural models, individuality and universality are repeatedly pointed out. As Glaveanu asserts, the dialogical ontogeny supporting socio-cultural models considers how identity and knowledge are co-constructed through interaction by sharing. The socio-cognitive models, in contrast, look at sharing as the ways in which group members code and decode information, translating it from the private to the public realm and vice versa while the moments if actual transformation happen inside the individual mental processor (Glaveanu, 2011). Glaveanu further maintains that the notion of universality also leads us to a divergence between socio-cognitive and socio-cultural models in that socio-cognitivists claim to be studying creativity per se; then, their conclusions are generalized to a great number of group situations. Socio-culturalists, in contrast, are interested in specificity of the context and of particular creative problem at hand and are inclined to show how the dynamics and even the meaning of creativity change across situations. However, although such differences are not contradictory, but complementary, and the common elements between socio-cognitive and socio-cultural models are seldom salient, the author is in an attempt to revitalize some of these commonalities.

The study of relationship between language and thought has become a bone of contention among practitioners in the history of second language acquisition. However, in essence, they are not that much different. Both share with this view that language acquisition is the result of social-cognitive construction. To better appreciate this relationship, always can a type of polarization be traced. On the one end, we have Vygotskey who asserts that language is the basis of thought; that is, it is language that forms thought. On the other end, we have Piaget who holds that thought is the fundamental 
cornerstone of language. As to Piaget, it is thought that forms language. Socio-cognitive approaches to language acquisition take advantage of Piagetian and Vygotskian perspectives toward second language acquisition. In effect, for both Piaget and Vygotsky, the social character is respected as a necessary aspect of human development (Tudge \& Rogoff, 1989).

To give a direction to our topic in order to better appreciate the notions of socio-cognitive approaches to second language acquisition, and see that socio-cognitive tenets are not so far from socio-cultural ones, two claims, according to Kecskes (2010), can be exercised on. First, speaker and hearer, considered as complete individuals, are equal participants in the communicative process. Second, communication is a dynamic process, in which individuals are not only constrained by societal conditions but they also shape at the same time. Thus, communication is the interplay of two traits: individual and social. Individual traits include attention, private experience, egocentrism and salience, while the latter-social traits-include intention, actual situational experience, cooperation and relevance. Accordingly, Kecskes defines communication as "the result of the interplay of intention and attention, as this interplay is motivated by the individuals' private socio-cultural backgrounds" (p. 58). Put similarly, socio-cognitive approaches reap the benefits of both pragmatic views and cognitive views. As to Kecskes and Zhang (2009), from pragmatic view, communication is considered as an intention-directed practice during which the interlocutors mutually recognize the intentions and goals, and make joint effort to achieve them (Clark, 1996, cited in Kecskes \& Zhang, 2009). Accordingly, Clark (1996) claims, "communication is supposed to be smooth if the speaker's intentions are recognized by the hearer through pragmatic inferences" (p. 335). What makes socio-cultural theory distinct from socio-cognitive is the fact that "the socio-cultural-interactional paradigm does not consider intention as central to communication" (Kecskes \& Zhang, 2009 , p. 336). The cognitive view of communication reports the egocentrism of speaker-hearers in mental processing of communication and postulated the emergent property of common ground. It is called egocentric as it is rooted in the speakers' or hearers' own knowledge instead of in mutual knowledge (Kecskes \& Zhang, 2009, p. 336). In a nutshell, in a socio-cognitive view, as claimed by Kecskes and Zhang (2009), "communication is the result of the interplay of intention and attention motivated by the socio-cultural background" (p. 338). They also maintain, "both cooperation and egocentrism are manifested in all phases of communication" (p. 338).

Kecskes (2010) also argues if we compare the pragmatic view and the cognitive view of communication, we see that the two approaches are not contradictory, but rather complement each other. Along the same line, Kecskes adds from a dialectical perspective, cooperation and egocentrism are not conflicting. Hence, the aim of the socio-cognitive approach is to eliminate the ostensible conflicts between the two views, and propose an approach that integrates their considerations into a holistic concept of communication (p. 58).

Glaveanu (2011) maintains that socio-cognitive approach and socio-cultural approach have relatively in common. More meticulously, considering the role of creativity, Glaveanu links collaborative creativity to socio-cultural framework, while socio-cognitive gets close to the concept of group creativity. From epistemological position, sociocognitive approach considers the social as external and creativity embedded in the mind, while in socio-cultural the social is considered as internal and creativity is embedded in interaction. This implies that language learning should not be respected "as an end itself to a child, but rather as a means of finding out about the world, of forming new concepts and associations" (Shakouri-Masouleh \& Bahraminezhad-Jooneghani, 2012, p. 1058). Nevertheless, the central issue among practitioners is that how these concepts are constructed. As to Piaget, a child appears to be an active participant and a sense maker (Cameron, 2001). Contending that the child is an active participant implies that while interacting with the world, the child constructs his or her view of the world in order to solve the problem alone. Shakouri-Masouleh and Bahraminezhad-Jooneghani (2012) state that the knowledge that results in this way is neither imitated nor inborn, but is relatively constructed. Piaget, in contrast with Vyogtsky, gives a less important role to language. To him cognitive development is the prerequisite of language development (Shakouri-Masouleh \& Bahraminezhad-Jooneghani, 2012). Furthermore, Piaget sees cognitive development as the process of maturation with which both genetics and experience interact. In such a way, as Brown (2000) states the developing mind is seeking equilibration. He continues that equilibration is accomplished by the two complementary processes of assimilation and accommodation. By assimilation, it is meant that the incoming information is modified so that can fit in what we knew earlier. Accommodation, in contrast, is defined as the modification of what we know in order to take into account new information. The term accommodation is coined restructuring in second language acquisition (Brown, 2000).

\section{B. Restructuring}

The idea of restructuring which is in contrast with proceduralization "refers to qualitative changes in the learners' interlanguage as they move from stage to stage" (Jordon, 2004, p. 211). While proceduralization entails accelerating learning processes performed more slowly by novices at the task, restructuring according to McLaughlin (1986, cited in Shakouri- Masouleh \& Bahraminezhad-Jooneghani, 2012) refers to the process of imposing a new organization on information already stored in long-term memory. In other words, as Mitchell and Myles (2004) puts forth, "restructuring destabilizes some structures in the interlanguage, which seemed to have been previously acquired, and hence leads to the temporary reappearance of second language errors" (p. 101).

For Vygotsky (1962), children's cognitive development is the result of interaction with other members of the society. In effect, socio-cultural theories place the social environment at the center of learning (Hall, 2007), and without which, the "development of the mind is impossible" (Cole \& Wertsch, 2001, cited in Hall, 2007, p. 96). Put similarly, to 
Vygotsky (cited in Shakouri-Masouleh \& Bahraminezhad-Jooneghani, 2012), language development is prerequisite to cognitive development, as language provides an individual with a tool. As Cameron (2001) states, language provides new chances for doing things and for organizing information through the use of words as symbols. In a nutshell, the child of Vygotsky, unlike Piaget's, is not alone (Shakouri-Masouleh \& Bahraminezhad-Jooneghani, 2012). The child of Vygotsky is born in public and is social. And the things around, either animate or inanimate, mediate the world for children and make it accessible to them (Shakouri-Masouleh \& Bahraminezhad-Jooneghani, 2012). Therefore, learning is the result of mediation. For this learning to occur, the participants employ tools-symbolic or physical. Cognitive development is not the direct result of activity, but it is indirect; other people play a part; they must interact and use tools as mediators that contribute to cognitive development. In other words, a learner has not yet learned but with help of his peers he/she is capable of learning (Brown, 2000).

To reap the benefit of socio-cognitive approach to language acquisition form Piaget's and Vygotsky's perspectives, some more recent socio-cultural theories provide examples of the ways that learners can be supported such as Rogoff's apprenticeship theory. Accordingly, as Matsuoka and Evans (2004) brought, Atkinson' socio-cognitive approach besides including Vygotsky's approach, uses Rogoff's apprenticeship theory (1990) and Lave and Wenger's theory of community of practice.

\section{Cognitive Apprenticeship Theory}

An impressive figure in the development of cognitive apprenticeship theory is Rogoff (1990). Disregarding the traditional meaning of apprenticeship as the attachment of a young person to the employer over a period of years, apprenticeship also involves formal education. However, the difference between apprenticeship and the other forms of learning is a matter of degree rather than kind. In the cognitive apprenticeship theory in education, the teacher, or more experienced peer, models the use mediatory tools and provides the scaffolding for learners to practice. Scaffolding is gradually withdrawn as the learner gains expertise (Hall, 2007). To give support to the cognitive development of learners, using strategies such as modeling, coaching, and fading are suggested by Rogoff (1990). Accordingly, modeling concerns providing examples of expert behavior that include explanations, coaching concerns encouragement, diagnosis, and direction; and scaffolding is the provision of structure or prompts in the learning environment. To provide further examples of cognitive apprenticeship, reciprocal teaching suggested by Palincsar and Brown (1984) is notable. As put by Palincsar and Brown (1984), reciprocal teaching is a dialogue held between teachers and students in order to jointly construct the meaning of text. They go on to hold that reciprocal teaching is designed to improve students' reading comprehension by teaching four key reading strategies: (1) summarizing the main content; (2) formulating questions; (3) clarifying ambiguities; and (4) predicting what may come next. In the same vein, Oliver (1999) maintains that in reciprocal teaching, the teacher models expert reading strategies such as making predictions, formulating questions, clarifying uncertain phrases/new vocabulary and verbally summarizing texts. Next, the teacher coaches and scaffolds students to use strategies correctly as they take turn applying them. At the end, the teacher's consistent guiding fades as the students become proficient in reading comprehension (Oliver, 1999).

Learning emerged as the result of apprenticeship inspired by the situated learning. Along the same line, situated learning theory suggests that learning is "naturally tied to authentic activity, context, and culture" (Brown, Collins, \& Duguid, 1989). Also, this theory suggests that it is more difficult to learn from un-natural activities. Situated learning examples include more "apprentice-like" situations such as carpenters, mechanics, printers, and sculptors (Oliver, 1999). According to Smith $(2003,2009)$ situational learning is more than learning by doing or experiential learning. Lave's and Weneger's concept of situatedness involves people being full participants in the world and in generating meaning (cited in Smiths, 2003, 2009). Tennant (1997) also reports that situated learning depends on two claims: (1) it makes no sense to talk of knowledge that is decontextualized, abstract or general; and (2) new knowledge and learning are properly conceived as being located in communities of practice.

\section{Community of Practice Theory}

The term community of practice as a component of social theory of learning has recently shouldered its way into the sociolinguistic lexicon. Wenger (1998b) uses it to critique traditional models of learning that knowledge was considered as a property and the teacher's responsibility was to transmit information in an artificial environment. Wenger suggests instead that learning is a natural and inevitable aspect of life, and a fundamentally social process (Holmes \& Meyerhoff, 1999). Wenger (1998b) identifies three crucial dimensions of community of practice: (1) mutual engagement, (2) a joint negotiated enterprise, and (3) a shared repertoire of negotiable resources accumulated over time. Mutual engagement entails regular interaction by the members of community. Joint negotiated enterprise implies the individuals in a community build their contributions toward the larger enterprise. It involves mutual accountability on the part of participants, and the shared repertoire shows that the joint pursuit of an enterprise results in a shared repertoire of joint resources for negotiated meaning. The sources might be linguistic (e.g., specialized terminology) or non-linguistic (e.g., pictures, gestures etc.). The members of the community might be either core or peripheral. The basis of this variation is how successfully an individual has acquired the shared repertoire.

The concept of a community of practice builds on a pedagogical tradition of viewing learning as a socially mediated activity (Campbell, 2007). Salomon (as cited in Campbell, 2007, p. 134) asserts that:

... a clearer understanding of human cognition would be achieved if studies were based on the concept that cognition 
is distributed among individuals, that knowledge is socially constructed through collaborative efforts to achieve shared objectives in cultural surroundings and that information is processed between individuals and tools and artifacts provided by the culture.

What Lave and Wenger (1991) argue is that the teacher-student relationship of an apprenticeship model of learning is in favor of a bilateral recognition of learning as shaping both the expert and the novice. This notion aligns with the ideas of Vygotsky, in particular, and socio-cultural learning, in general (Campbell, 2007).

Vygotsky, in support of apprentice-like coaching, holds that the acquirement of task in a community of practice must be situated in ZPD. The term ZPD connotes the distance between individual's existing developmental level and his/her potential level. That is, learning task must be beyond what a student can accomplish alone; however, it must be at the level of impossibility. Thus to get to the level of achievement, one must be scaffolded.

\section{E. Situated Learning}

Situated learning was earlier projected by Lave and Wenger (1991) who introduced the communities of practice (Engeström, 2007). Put simply, this type of learning, i.e., situated learning, occurs in the context not in the abstract (Vincini, 2003). Lave and Wenger (1991) argue that learning should not be considered as simply the transmission of decontextualized knowledge from one person to another. To Lave and Wenger learning is respected as a social process whereby knowledge is cooperatively constructed; they, henceforth, assert that this type of learning is situated in a specific context and embedded within a particular social and physical environment. Accordingly, Sholes (2003) continues in situated learning, students learn content through immersion in the activities of their discipline of study. From ecological perspective, posited by van Lier (2000), cognition is situated or viewed in terms of the relationship between the learners and the specific environment (Haas, 2003).

However, as Liu and Matthews (2005) maintain, "the philosophy underpinning situativity theory is that individuals as non-initiative beings receive one-sided external forces from the social" (p. 392). Hence, the ecological tenets of situativity connote the notion of direct perception without the need for mediating variables that exist in one's head. The epistemology of situativity is thus inspired from direct realism. Instead of viewing experiences as constituting the mind, the existence of the mind is suggested.

Although Vygotsky is associated with situated learning theory, several scholars hold his theory is not social enough (Liu \& Matthews, 2005). As Liu and Mattews state, "Lave and Wenger (1991), for example, in postulating their situated learning theory, disapproves of Vygotsky's concept of learning internalization, generalization, and scientific concepts, for they contain only a small aura of socialness that provides input for the process of internalization, viewed as individualistic acquisition of the cultural given" (p. 391). Vygotsky takes a dualistic perspective towards the social and the individual. In the same line, Renick (1996 cited in Liu \& Mattews, 2005) holds Vygotsky ignores the role of individual and fails to address how the external world is bridged across the internal mind (Fox, 2001, cited in Liu \& Mattews, 2005, p. 391). In sum, Vygotsky's idea is more or less socially relativist, as he considers the multiplicity of peer perspectives (Tsai, 2012). What is explicit in Tsai's (2012) claim is that in Vygotsky's theory, the central aim of education is the development of intellect and rationality beyond situations.

Situated learning also proposes that learning involves a process of engagement in a community of practice (Lave \& Wenger, 1991). Looking closely at everyday activity, Lave (1993) has argued, it is clear that "learning is ubiquitous in ongoing activity, though often unrecognized as such" (Lave, 1993, p. 5). He later with Wenger develops a theory called theory of community of practice. Thus, communities of practice are groups of people who share a concern or a passion for something they do and learn how to do it better as they interact regularly (Wenger, 2007). What brought the members of communities are the activities and what they have learned through their mutual engagement in their activities (Wenger 1998a). Moreover, Wenger (2007) argues that three elements are essential in distinguishing a community of practice from other groups and communities: the domain, the community, and the practice. The domain of community implies that the member of which have commitments to it; thus, a shared competence makes the members of which distinct from other people. In pursuing their interest in their domain, members of the community getting engaged in shared activities help each other and share information. Also, the members of community develop a shared repertoire of resources: experiences, stories, tools, etc. Accordingly, for a community of practice to function well, it needs to generate and appropriate a shared repertoire of ideas, commitments, and memories. It is worth mentioning, for this whole to occur, it needs to get involved in praxis. Praxis involves a give-and-take relationship between theory and practice-between theorizing practice and practicing theory. As Freir (1985, cited in Monchinski, 2008) warns "Cut-off from practice theory becomes a simple verbalism and separated from theory is nothing but blind activism" (p. 1-2). In Freire's philosophy, praxis and dialogue are closely related: genuine dialogue represents a form of humanizing praxis.

\section{CONCLUSION}

What socio-cognitive approaches share with socio-cultural approaches is that their ontology is relativistic and its epistemology is subjective. In sum, the ways in which the world is viewed are different. As each one perceives the world from his/her own point of view. Furthermore, this meaning is only interpreted with respect to relationships. Thus, it is impossible to learn by discovering what is in the head or in the outside world. The notion of 'social mind' 
(Matsuoka \& Evans, 2004) is the product of social interaction. Hence, as Atkinson (2002) insists "language is always mutually, simultaneously and co-constitutively in the head and in the world" (p.537) - between inside schema and outside tool. Accordingly, Atkinson touches down on four implications of socio-cognitive approach to SLA: (1) the apprentice learns from the master in the classroom as well as the world outside the classroom; (2) viewing language as social connotes that second language acquisition is able to reinforce related fields such as discourse, identity and culture; (3) considering humans as holistic in existence, the employment of qualitative research in general and ethnography in particular; and (4) through learning one's identities are going to be constructed. Along the same line, Smiths (2009) inspiring from the notion of community of practice, provides three significant pointers of practice: (1) learning is situated through the interrelationship among people; (2) people are regarded as the active participants in communities of practice; and (3) knowledge and activity are highly connected.

As stated earlier, cooperation and egocentrism are the necessary tools for promoting communication. For communication to take place, a sophisticated degree of empathy is going to be established. If empathy is established, a considerable degree of cooperation is established that is considered pivotal. From the other side, by egocentrism, it is meant "that interlocutors activate the most salient information to their attention in the construction (speaker) and comprehension (hearer) of communication" (Kecskes \& Zhang, 2009, p. 343).

\section{REFERENCES}

[1] Atkinson, D. (2002). Toward a sociocognitive approach to second language acquisition. Modern Language Journal, 86, 525545

[2] Brown, H. D. (2000). Principles of language learning and teaching. Longman: Person Education Company.

[3] Brown, J. S., Collins, A., \& Duguid, P. (1989). Situated cognition and the culture of learning. Educational Researcher, 18 (1), $32-41$.

[4] Cameron, J. (2001). Teaching language to young learners. Cambridge: Cambridge university press.

[5] Campbell, M. (2007). Applying communities of practice to the learning of police. Learning and sociocultural theory: Exploring modern Vygotskian perspectives international Workshop 2007, 1(1), 2007. Retrieved in 2013 from http://ro.uow.edu.au/llrg/vol1/iss1/9.

[6] Engeström, Y. (2007). From communities of practice to mycorrhizae. In J. Hughes, N. Jewson, \& L. Unwin (Eds.), Communities of practice: Critical perspectives (pp. 1-20). London: Routledge.

[7] Glaveanu, V. P. (2011). How are we creative together? Comparing sociocognitive and sociocultural answers. Theory \& Psychology, 21 (4), 473-492. Doi: 10.1177/0959354310372152.

[8] Haas, G. (2003). Smart people or smart context? Cognition, ability, and talent development in an age of situated approaches to knowing and learning. Retrieved in 2012 from http://uit.tufts.edu/at/downloads/newsletter_feb_2003.pdf.

[9] Hall, A. (2007). Vygotsky goes online: Learning design from a socio-cultural perspective. Research on Line, 1 (6), 93-107.

[10] Holmes, J., \& Meyerhoff, M. (1999). The community of practice: Theories and methodologies in language and gender research. Language in Society, 28, 173-183.

[11] Jordon, G. (2004). Theory construction in second language acquisition. Philadelphia: John Benjamins.

[12] Kecskes, I. (2010). The paradox of communication: socio-cognitive approach to pragmatics. Pragmatics and Society, 1 (1), 5073. Doi. 10.1075/ps.1.104kec.

[13] Kecskes, I, \& Zhang, F. (2009). Activating, seeking and creating common ground. Pragmatics \& Cognition, 17 (2), $331-335$. Doi $10.1075 / \mathrm{p} \& \mathrm{c} .17 .2 .06 \mathrm{kec}$.

[14] Lave, J. (1993). The practice of learning. In S. Chaiklin \& J. Lave (eds.), Understanding practice: perspectives on activity and context (pp. 3-32). New York: Cambridge University Press.

[15] Lave, J., \& Wenger, E. (1991). Situated learning. Legitimate peripheral participation. Cambridge: University of Cambridge Press

[16] Liu, C. H., \& Matthews, R. (2005). Vygotsky's philosophy: Constructivism and its criticisms examined. International Education Journal, 6 (3), 386-399.

[17] Matsuoka, R., \& Evans, D. R. (2004). Socio-cognitive approach in second language acquisition research. J Nurs Studies, 3 (1), $1-10$.

[18] Meskill, C. \& Rangelova, K. (2000). Relocating the 'cognitive' in sociocognitive views of second language learning. In R. Rapp (Ed), Linguistics on the way into the new millennium: Proceedings of the 34 colloquium of linguistics. London: Peter Lang-Verlag Publishing.

[19] Mislevy, R. J. (2008). Some implications of expertise research for educational assessment. Retrieved in 2012 from $w w w$.eric.ed.gov/ERICWebPortal/recordDetail?accno=EJ893150.

[20] Mitchell, R., \& Myles, F. (2004). Second language learning theories (2nd $)$. London: Hodder Arnold.

[21] Monchinski, T. (2008). Critical pedagogy and the everyday classroom. London: Springer.

[22] Oliver, K. (1999). Situated cognition \& cognitive apprenticeships. Retrieved in 2012 from http://www.edtech.vt.edu/edtech/id/models/powerpoint/cog.pdf.

[23] Palincsar, A., \& Brown, A. (1984). Reciprocal teaching of comprehension-fostering and comprehension monitoring activities. Cognition and Instruction, 1, 117-175.

[24] Rogoff, B. (1990). Apprenticeship in thinking: Cognitive development in social context. New York: Oxford University Press.

[25] Shakouri-Masouleh, N., \& Bahraminezhad-Jooneghani, R. (2012). The secrecy underlying young language learners' learning. Paper presented at World Academy of Science and Technology 66 2012, Paris.

[26] Sholes, R. (2003). E-Government: A course in situated learning. Retrieved in 2012from http://uit.tufts.edu/at/downloads/newsletter_feb_2003.pdf. 
[27] Smith, M. K. (2009). Communities of practice: The encyclopedia of informal education, Retrieved in 2013 from www.infed.org/biblio/communities_of_practice.htm.

[28] Tennant, M. (1997). Psychology and adult learning. London: Routledge.

[29] Tsai, C. C. (2012). The development of epistemic relativism versus social relativism via online peer assessment, and their relations with epistemological beliefs and internet self-efficacy. Educational Technology \& Society, 15 (2), 309-316.

[30] Tudge, J., \& Rogoff, B. (1989). Peer influences on cognitive development: Piagetian and Vygotskian perspectives. In J. S. B. E. Marc \& H. Bornstein (Eds.), Interaction in human development. crosscurrents in contemporary psychology (pp. 17-40). New Jersey: Lawrence Erlbaum Associates.

[31] van Lier, L. (2000). From input to affordance: Social interactive learning from an ecological perspective. In J. P. Lantolf (Ed.), Sociocultural theory and second language learning: Recent advances (pp. 245-259). Oxford: Oxford University Press.

[32] Vincini, P. (2003). The nature of situated learning. Retrieved in 2013 from http://uit.tufts.edu/at/downloads/newsletter_feb_2003.pdf.

[33] Vygotsky, L. (1962). Thought and language. Cambridge, MA: MIT Press.

[34] Wenger, E. (1998a). Communities of Practice. Learning as a social system. Systems Thinker, Retrieved in 2013 from http://www.co-i-l.com/coil/knowledge-garden/cop/lss.shtml.

[35] Wenger, E. (1998 b). Communities of practice. Cambridge: Cambridge University Press.

[36] Wenger, E. (2007). Communities of practice. A brief introduction. Communities of practice Retrieved in 2013 from http://www.ewenger.com/theory/.

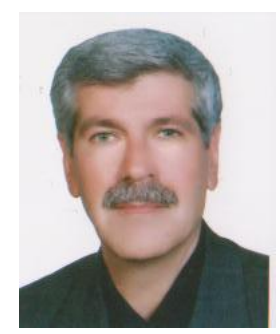

Mohammad Khatib is the assistant professor at Allameh Tabataba'i University, Tehran, Iran. He has published numerous articles in the area of TEFL. Needless to say, he delivers Ph.D. courses, such as Learning Theories and Teaching English Literature.

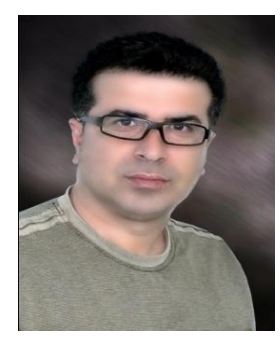

Nima Shakouri is the Ph.D. candidate of TEFL at Islamic Azad University, Science and Research, Tehran, Iran. His research interests include psychology of language learning, critical discourse analysis and critical pedagogy. 